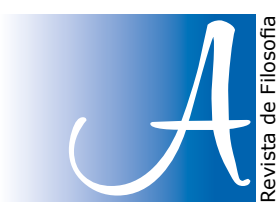

ARGUMENTOS

\title{
An intermediate term functor logic
}

\author{
Uma lógica de termos intermediários
}

\begin{abstract}
In this paper we attempt to do something rather simple: to meet the advances of Sommers and Englebretsen (namely, a plus-minus algebra for syllogistic) together with the developments of Peterson and Thompson (namely, an extension of syllogistic with "most," "many," and "few"). The result is an intermediate syllogistic that copes with a wide range of logical patterns but with the virtues of an algebraic approach.
\end{abstract}

Keywords: Plus-minus algebra. Non-classical quantifiers. Common sense reasoning.

\section{RESUMO}

Neste artigo, tentamos fazer algo bastante simples: conhecer os avanços de Sommers e Englebretsen (a saber, uma álgebra mais-menos para silogística) juntamente com os desenvolvimentos de Peterson e Thompson (ou seja, uma extensão da silogística com "a maioria", "Muitos" e "poucos"). O resultado é uma silogística intermediária que lida com uma ampla gama de padrões lógicos, mas com as virtudes de uma abordagem algébrica.

Palavras-chave: Álgebra mias-menos. Quantificadores adicionais. Raciocínio de senso comum.

\section{Introduction}

In this paper we attempt to do something rather simple: to meet the advances of Sommers (SOMMERS, 1967, 1982; SOMMERS and ENGLEBRETSEN, 2000) and Englebretsen (ENGLEBRETSEN, 1987, 1996; ENGLEBRETSEN and SAYWARD, 2011) (namely, a plus-minus algebra for syllogistic) together with the developments of Peterson (1979) and Thompson (1982) (namely, an extension of syllogistic with "most," "many," and "few"). The plus-minus calculus, on the one hand, provides a

* Doctor en Filosofía de la Ciencia. https://orcid.org/0000-0003-2227-921X 
logically sound and complete algebraic approach for syllogistic that, alas, does not cover cases of common sense reasoning involving non-classical quantifiers such as "most," "many," or "few;" whereas, on the other hand, the syllogistic extended with non-classical quantifiers comprises a wide range of common sense inference patterns but, unfortunately, it lacks an algebraic procedure.

So, given this state of affairs, in this study we offer a tweaked version of syllogistic that includes such a broad range of inferential patterns but with the virtues of an algebraic approach. The outcome is a logical framework that gains the advantages of an algebraic method (a reduction of a complex set of rules into a simple and unified formal approach) and, at the same time, the advantages of a theory of syllogisms with non-classical quantifiers (an assessment of a wide range of common sense inference patterns that extends the scope of traditional syllogistic). To reach this result we briefly present the frameworks previously mentioned, we introduce our contribution and, at the end, we succinctly mention some possible uses of this modified syllogistic.

\section{Two frameworks for syllogistic}

\section{General aspects of syllogistic}

Syllogistic (SYLL) is a term logic that has its origins in Aristotle's Prior Analytics and deals with inference between categorical propositions. A categorical proposition is a proposition composed by two terms, a quantity, and a quality. The subject and the predicate of a proposition are called terms: the term-schema $\mathrm{S}$ denotes the subject term of the proposition and the term-schema $\mathrm{P}$ denotes the predicate. The quantity may be either universal (All) or particular (Some) and the quality may be either affirmative (is) or negative (is not). These categorical propositions have a type denoted by a label (either a (for the universal affirmative, $\mathrm{SaP}$ ), e (for the universal negative, $\mathrm{SeP}$ ), i (for the particular affirmative, $\mathrm{SiP}$ ), or o (for the particular negative, SoP)) that allows us to determine a mood, that is, a sequence of three categorical propositions ordered in such a way that two propositions are premises and the last one is a conclusion. A categorical syllogism, then, is a mood with three terms one of which appears in both premises but not in the conclusion. This particular term, usually denoted with the term-schema $\mathrm{M}$, works as a link between the remaining terms and is known as the middle term. According to the position of this middle term, four arrays or figures can be set up in order to encode the valid syllogistic moods (Table 1 ). ${ }^{1}$

Table 1 - Valid syllogistic moods in SYLL

\begin{tabular}{cccc}
\hline Figure 1 & Figure 2 & Figure 3 & Figure 4 \\
\hline aaa & eae & iai & aee \\
eae & aee & aii & iai \\
aii & eio & oao & eio \\
eio & aoo & eio & \\
\hline
\end{tabular}

${ }^{1}$ For sake of brevity, but without loss of generality, here we omit the syllogisms that require existential import. 
The System TFL. Term functor logic

Sommers (1967, 1982; SOMMERS and ENGLEBRETSEN, 2000) and Englebretsen (ENGLEBRETSEN，1987，1996; ENGLEBRETSEN and SAYWARD, 2011) developed a plus-minus algebra, Term Functor Logic (TFL), that deals with syllogistic by using terms rather than first order language elements such as individual variables or quantifiers. ${ }^{2}$ According to this algebra, the four categorical propositions can be represented by the following syntax: ${ }^{3}$

- $\mathrm{SaP}:=-\mathrm{S}+\mathrm{P}=-\mathrm{S}-(-\mathrm{P})=-(-\mathrm{P})-\mathrm{S}=-(-\mathrm{P})-(+\mathrm{S})$

- $\mathrm{SeP}:=-\mathrm{S}-\mathrm{P}=-\mathrm{S}-(+\mathrm{P})=-\mathrm{P}-\mathrm{S}=-\mathrm{P}-(+\mathrm{S})$

- $\mathrm{SiP}:=+\mathrm{S}+\mathrm{P}=+\mathrm{S}-(-\mathrm{P})=+\mathrm{P}+\mathrm{S}=+\mathrm{P}-(-\mathrm{S})$

- $\mathrm{SoP}:=+\mathrm{S}-\mathrm{P}=+\mathrm{S}-(+\mathrm{P})=+(-\mathrm{P})+\mathrm{S}=+(-\mathrm{P})-(-\mathrm{S})$

Given this algebraic representation, the plus-minus algebra offers a simple method of decision for syllogistic: a conclusion follows validly from a set of premises if and only if $i$ ) the sum of the premises is algebraically equal to the conclusion and ii) the number of conclusions with particular quantity (viz., zero or one) is the same as the number of premises with particular quantity (Englebretsen 1996, p. 167). Thus, for instance, if we consider a valid syllogism, say the mood aaa from figure 1 , we can see how the application of this method produces the right conclusion (Table 2).

Table 2 - A valid syllogism: aaa-1

\begin{tabular}{lll}
\hline & Proposition & Representation \\
\hline 1. & All dogs are animals. & $-\mathrm{D}+\mathrm{A}$ \\
2. & All German Shepherds are dogs. & $-\mathrm{G}+\mathrm{D}$ \\
$\vdash \quad$ All German Shepherds are animals. & $-\mathrm{G}+\mathrm{A}$ \\
\hline
\end{tabular}

In the previous example we can clearly see how the method works: $i)$ if we add up the premises we obtain the algebraic expression $(-D+A)+(-G+D)=-$ $D+A-G+D=-G+A$, so that the sum of the premises is algebraically equal to the conclusion and the conclusion is $-G+A$, rather than $+A-G$, because ii) the number of conclusions with particular quantity (zero in this case) is the same as the number of premises with particular quantity (zero in this case).

This algebraic approach is also capable of representing relational, singular, and compound propositions with ease and clarity while preserving its main idea, namely, that inference is a logical procedure between terms. For example, the following cases illustrate how to represent and perform inference with relational

\footnotetext{
2 That we can perform inference without first order language elements such as individual variables or quantifiers is not news (cf. Quine (1971); Noah (1980); Kuhn (1983)), but Sommers' logical project has a wider impact: that we can use a logic of terms instead of a first order system has nothing to do with the mere syntactical fact, as it were, that we can reason without quantifiers or variables, but with the general view that natural language is a source of natural logic (cf. Sommers (2005); Moss (2015)).

${ }^{3}$ We mainly focus on the presentation by Englebretsen (1996).
} 
(Table 3), singular ${ }^{4}$ (Table 4), or compound propositions ${ }^{5}$ (Table 5). For a brief but systematic explanation of the rules employed in what follows vide Appendix A.

Table 3 - An inference with relational propositions

\begin{tabular}{llll}
\hline & Proposition & Representation & Rule \\
\hline 1. & Some horses are faster than some dogs. & $+\mathrm{H}+(+\mathrm{F}+\mathrm{D})$ & $\mathrm{P}$ \\
2. & Dogs are faster than some men. & $-\mathrm{D}+(+\mathrm{F}+\mathrm{M})$ & $\mathrm{P}$ \\
3. The relation faster than is transitive. & $-(+\mathrm{F}+(+\mathrm{F}+\mathrm{M}))+(+\mathrm{F}+\mathrm{M})$ & $\mathrm{P}$ \\
4. & & $+\mathrm{H}+(+\mathrm{F}+(+\mathrm{F}+\mathrm{M}))$ & DON 1,2 \\
$\vdash \quad$ Some horses are faster than some men. & $+\mathrm{H}+(+\mathrm{F}+\mathrm{M})$ & DON 3,4 \\
\hline
\end{tabular}

Table 4 - An inference with singular propositions

\begin{tabular}{llll}
\hline & Proposition & Representation & Rule \\
\hline 1. & All men are mortal. & $-\mathrm{M}+\mathrm{L}$ & $\mathrm{P}$ \\
2. & Socrates is a man. & $+\mathrm{s}+\mathrm{M}$ & $\mathrm{P}$ \\
$\vdash$ & Socrates is mortal. & $+\mathrm{s}+\mathrm{L}$ & $\mathrm{DON} 1,2$ \\
\hline
\end{tabular}

Table 5. An inference with compound propositions

\begin{tabular}{llll}
\hline & Proposition & Representation & Rule \\
\hline 1. If you are Socrates, you are Plato's friend. & $-[\mathrm{s}]+[\mathrm{p}]$ & $\mathrm{P}$ \\
2. You are Socrates. & $+[\mathrm{s}]$ & $\mathrm{P}$ \\
$\vdash \quad$ You are Plato's friend. & $+[\mathrm{p}]$ & DON 1,2 \\
\hline
\end{tabular}

The System SYLL+. Intermediate syllogistic

Peterson (1979) and Thompson (1982) developed extensions for syllogistic $\left(\mathrm{SYLL}^{+}\right.$) by adding some extra quantifiers, namely, "most" (for majority propositions), "many" (for common propositions), and "few" (for predominant propositions). So, this framework adds the next propositions: $\mathrm{p}$ is the predominant affirmative ( Few $\mathrm{S}$ are not $\mathrm{P}), \mathrm{b}$ is the predominant negative $(\mathrm{Few} \mathrm{S}$ are $\mathrm{P}), \mathrm{t}$ is the majority affirmative (Most $\mathrm{S}$ are $\mathrm{P}$ ), $\mathrm{d}$ is the majority negative (Most $\mathrm{S}$ are not $\mathrm{P}), \mathrm{k}$ is the common affirmative (Many $\mathrm{S}$ are $\mathrm{P}$ ), and $\mathrm{g}$ is the common negative (Many $\mathrm{S}$ are not $\mathrm{P}$ ).

According to (Thompson, 1982, 76), the semantics of these new quantifiers may be understood in any of three senses: minimal, maximal, and exact. A quantifier in the minimal sense is understood to be saying "at least" or "no less than" the quantity named. A quantifier in the maximal sense is understood to be saying "only" or "no more than" the quantity stated. A quantifier in the exact sense combines the minimal and maximal senses, so that it says "no more nor less than." Given this taxonomy, Thompson uses "many" and "most" in a minimal sense, just as "some" is traditionally understood as meaning "at least some (and possibly all)." Meanwhile, Thompson restricts "few" to its maximal sense as to mean "no more than few (if any)." This results in the notion that "few" must be understood to be making a denial, and this explains why the proposition Few $\mathrm{S}$ are $\mathrm{P}$ is regarded as the predominant negative, whereas Few $\mathrm{S}$ are not $\mathrm{P}$ is taken as the

\footnotetext{
${ }^{4}$ Provided singular terms, such as Socrates, are represented by lowercase letters.

${ }^{5}$ Given that compound propositions can be represented as follows, $\mathrm{P}:=+[\mathrm{p}], \mathrm{Q}:=+[\mathrm{q}], \neg \mathrm{P}:=-[\mathrm{p}], \mathrm{P} \rightarrow \mathrm{Q}:=-[\mathrm{p}]+[\mathrm{q}]$,

$\mathrm{P} \wedge \mathrm{Q}:=+[\mathrm{p}]+[\mathrm{q}]$, and $\mathrm{P} \vee \mathrm{Q}:=--[\mathrm{p}]--[\mathrm{q}]$, the method of decision behaves like binary resolution (cf. Noah, 2005).
} 
predominant affirmative. All these semantic remarks result in an extended square of opposition (Figure 1).

Figure 1 - Extended square of opposition (adapted from (Thompson, 1982, 77)

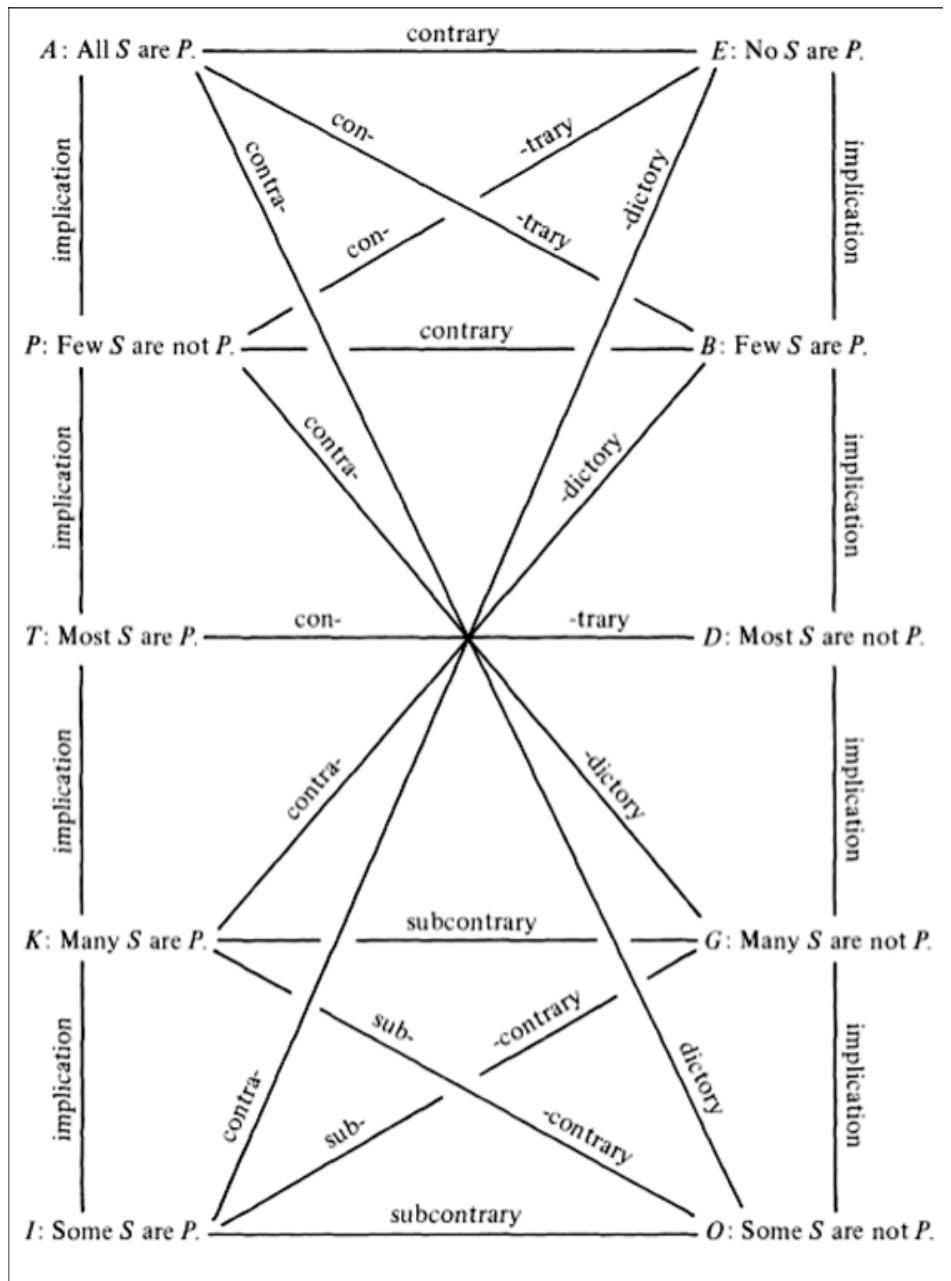

Given these new propositions, SYLL ${ }^{+}$adds some basic assumptions of distribution: any universal proposition distributes its subject; any negative proposition distributes its predicate; any predominant, majority, or common proposition distributes its subject if and only if its subject is the minor term. With these basic assumptions, the $\mathrm{SYLL}^{+}$framework provides the next rules of validity:

1. Rules of distribution.

a. The middle term must be distributed in at least one premise.

b. Any term which is distributed in the conclusion must also be distributed in the premises.

2. Rules of quality.

a.There must be at least one affirmative premise.

b. If the conclusion is negative, there must be at least one negative premise.

c. If there is a negative premise, then the conclusion must be negative.

3. Rules of quantity. 
a. If there is a predominant premise, the conclusion may not be universal.

b. If there is a majority premise, the conclusion may not be universal or predominant.

c. If there is a common premise, the conclusion may not be universal, predominant, or majority.

It is clear this framework allows us to extend syllogistic as to cope with a wide range of common sense inference patterns, both valid (Table 6) and invalid (Table 7. As expected, the addition of $p, t, k, b, d$, and $g$ increases the number of valid moods (Table 8 ).

Table 6 - A valid inference: aat-1

\begin{tabular}{lll}
\hline \multicolumn{2}{l}{ Proposition } & Representation \\
\hline 1. & All humans are mortal. & $\mathrm{HaM}$ \\
2. All Greeks are humans. & $\mathrm{GaH}$ \\
$\vdash \quad$ Most Greeks are mortal. & $\mathrm{GtM}$ \\
\hline
\end{tabular}

Table 7 - An invalid inference: tta-1

\begin{tabular}{lll}
\hline & Proposition & Representation \\
\hline 1. & Most humans are mortal. & $\mathrm{HtM}$ \\
2. Most Greeks are humans. & $\mathrm{GtH}$ \\
H & All Greeks are mortal. & $\mathrm{GaM}$ \\
\hline
\end{tabular}

Table 8 - Extension of the valid moods in SYLL

\begin{tabular}{|c|c|c|c|c|}
\hline & Figure 1 & Figure 2 & Figure 3 & Figure 4 \\
\hline \multirow{6}{*}{ With "most" } & aat & aed & & \multirow{6}{*}{$\begin{array}{l}\text { aed } \\
\text { eto } \\
\text { tai }\end{array}$} \\
\hline & att & add & ati & \\
\hline & ati & ado & eto & \\
\hline & ead & ead & tai & \\
\hline & etd & etd & dao & \\
\hline & eto & eto & & \\
\hline \multirow{8}{*}{$\begin{array}{l}\text { With } \\
\text { "many" }\end{array}$} & aak & aeg & & \multirow{8}{*}{$\begin{array}{l}\text { aeg } \\
\text { eko } \\
\text { kai }\end{array}$} \\
\hline & atk & adg & & \\
\hline & aki & ago & aki & \\
\hline & akk & agg & eko & \\
\hline & eag & eag & kai & \\
\hline & etg & etg & gao & \\
\hline & eko & eko & & \\
\hline & ekg & ekg & & \\
\hline \multirow{10}{*}{ With "few" } & aap & aeb & & \multirow{10}{*}{$\begin{array}{l}\text { aeb } \\
\text { pai } \\
\text { epo }\end{array}$} \\
\hline & app & $a b b$ & & \\
\hline & apt & abd & & \\
\hline & apk & abg & pai & \\
\hline & api & abo & epo & \\
\hline & eab & eab & bao & \\
\hline & epb & epb & api & \\
\hline & epd & epd & & \\
\hline & epg & epg & & \\
\hline & epo & epo & & \\
\hline
\end{tabular}

Fonte: adapted from Thompson (1982) 


\section{The System TFL ${ }^{+}$. Intermediate term functor logic}

The plus-minus algebra, as we have seen, provides a simple and logically sound algebraic approach for syllogistic that, alas, does not cover cases of common sense reasoning involving non-classical quantifiers such as "most," "many," or "few;" on the other hand, the syllogistic extended with non-classical quantifiers comprises a wide range of common sense inference patterns but, unfortunately, it lacks an algebraic procedure. So, given this state of affairs, we produce a tweaked version of syllogistic that includes such a broad range of inferential patterns but with the virtues of an algebraic approach. In order to reach this goal, we proceed in three steps. First we propose a modified syntax of the TFL framework as to include a way to represent the extra quantifiers of the SYLL framework, then we modify the method of decision of the plus-minus algebra, and finally we show this modification is reliable.

\section{Step 1. The plus-minus algebra meets the extra quantifiers}

In order to represent propositions $\mathrm{p}, \mathrm{t}, \mathrm{k}, \mathrm{b}, \mathrm{d}$, and $\mathrm{g}$ within the framework of the plus-minus algebra, let us consider the proposal displayed in Table 9.

Table 9 - Representation of the syllogistic propositions

\begin{tabular}{clcclc}
\hline Proposition & & Representation & Proposition & & Representation \\
\hline $\mathrm{SaP}$ & $:=$ & $-\mathrm{S}^{0}+\mathrm{P}^{0}$ & $\mathrm{SeP}$ & $:=$ & $-\mathrm{S}^{0}-\mathrm{P}^{0}$ \\
$\mathrm{SpP}$ & $:=$ & $+\mathrm{S}^{3}+\mathrm{P}^{0}$ & $\mathrm{SbP}$ & $:=$ & $+\mathrm{S}^{3}-\mathrm{P}^{0}$ \\
$\mathrm{StP}$ & $:=$ & $+\mathrm{S}^{2}+\mathrm{P}^{0}$ & $\mathrm{SdP}$ & $:=$ & $+\mathrm{S}^{2}-\mathrm{P}^{0}$ \\
$\mathrm{SkP}$ & $:=$ & $+\mathrm{S}^{1}+\mathrm{P}^{0}$ & $\mathrm{SgP}$ & $:=$ & $+\mathrm{S}^{1}-\mathrm{P}^{0}$ \\
$\mathrm{SiP}$ & $:=$ & $+\mathrm{S}^{0}+\mathrm{P}^{0}$ & $\mathrm{SoP}$ & $:=$ & $+\mathrm{S}^{0}-\mathrm{P}^{0}$ \\
\hline
\end{tabular}

The rationale behind this proposal is simple: conforming to the SYLL ${ }^{+}$ framework, non-universal intermediate propositions, namely $\mathrm{p}(\mathrm{b}), \mathrm{t}(\mathrm{d})$, and $\mathrm{k}(\mathrm{g})$, are particular to some extent, just like type $\mathrm{i}$ (o) propositions, and that requires us to pick, following the TFL framework, a +/+ combination of terms for the positive propositions; and a $+/-$ combination of terms for the negative. However, this is not enough because, according to the SYLL ${ }^{+}$framework, propositions $p(b), t(d)$, and $\mathrm{k}(\mathrm{g})$ are not convertible, ${ }^{6}$ and so, they are not equivalent to propositions of type $\mathrm{i}(\mathrm{o})$, which forces us to use some sort of flag in order to explicitly denote this fact: we use superscript indexes.

Now, according to the SYLL ${ }^{+}$framework, the new quantifiers imply some sort of order ( $\mathrm{p}(\mathrm{b})$ implies $\mathrm{t}(\mathrm{d}), \mathrm{t}(\mathrm{d})$ implies $\mathrm{k}(\mathrm{g})$, and $\mathrm{k}(\mathrm{g})$ implies $\mathrm{i}(\mathrm{o})$, as in Figure 1) and so the superscript indexes are used not only as flags but also as ordered levels of quantification. This choice has the following features: propositions $\mathrm{a}, \mathrm{e}, \mathrm{i}$, and o have level 0 to denote the fact that they behave as usual, as if no

\footnotetext{
${ }^{6}$ So, for example, $\mathrm{t}:=$ Most Americans speak English is particular, just like i:=Some Americans speak English, but clearly $\mathrm{t}$ is not convertible and thus it is not equivalent to i: regard that if Some Americans speak English then surely Some English speakers are American, but Most Americans speak English does not entail Most English speakers are American. Similar counterexamples can be developed to show that propositions $\mathrm{p}(\mathrm{b}), \mathrm{t}(\mathrm{d})$, and $\mathrm{k}(\mathrm{g})$ do not collapse into $\mathrm{i}(\mathrm{o})$ propositions.
} 
modifications were made; the superscript indexes are attached to both terms as to specify the detail that propositions $\mathrm{p}, \mathrm{t}, \mathrm{k}, \mathrm{b}, \mathrm{d}$, and $\mathrm{g}$ are not convertible; and also, such indexes help us induce an order $(3 \geq 2 \geq 1 \geq 0)$ that indicates that a (e) does not entail p (b), t (d), k (g), i (o); but p (b), t (d), k (g) do entail i (o). ${ }^{7}$

\section{Step 2. The plus-minus algebra modification}

Given this new representation, the modification of the plus-minus algebra method of decision is as follows: a conclusion follows validly from a set of premises if and only if $i$ ) the sum of the premises is algebraically equal to the conclusion, ii) the number of conclusions with particular quantity is the same as the number of premises with particular quantity, and iii) the level of quantification of the conclusion is lesser or equal than the maximum level of quantification of the premises. To exemplify this procedure, let us consider a couple of examples, one valid (Table 10), one invalid (Table 11).

Table 10 - att-1

\begin{tabular}{lll}
\hline & Proposition & Representation \\
\hline 1. & All $\mathrm{H}$ are $\mathrm{M}$. & $-\mathrm{H}^{0}+\mathrm{M}^{0}$ \\
2. & Most G are H. & $+\mathrm{G}^{2}+\mathrm{H}^{0}$ \\
$\vdash \quad$ Most G are M. & $+\mathrm{G}^{2}+\mathrm{M}^{0}$ \\
\hline
\end{tabular}

Table 11 - tta-l

\begin{tabular}{lll}
\hline & Proposition & Representation \\
\hline 1. & Most $\mathrm{H}$ are $\mathrm{M}$. & $+\mathrm{H}^{2}+\mathrm{M}^{0}$ \\
2. & Most G are H. & $+\mathrm{G}^{2}+\mathrm{H}^{0}$ \\
$\forall$ & All G are M. & $-\mathrm{G}^{0}+\mathrm{M}^{0}$ \\
\hline
\end{tabular}

The performance of this tweaked version of syllogistic may be better appreciated by considering the trade-off between the complexity of the SYLL ${ }^{+}$ framework and the expressive power of the TFL framework regarding common sense reasoning with non-classical quantifiers. To illustrate this, let us consider some examples (Tables 13-16). ${ }^{8}$ As expected, this intermediate syllogistic allows the valid inference patterns displayed in Table $12 .^{9}$

Table 12 - Valid syllogistic moods with extra quantifiers in the TFL+ framework

\begin{tabular}{cccc}
\hline & Figure 2 & Figure 3 & Figure 4 \\
\hline & add & ati & \\
With "most" & ado & eto & eto \\
& etd & tai & tai \\
& eto & dao & \\
\hline
\end{tabular}

\footnotetext{
${ }_{7}$ This is different from the original presentation by Thompson (1982). Thompson allows universal propositions entail particular propositions, but our version follows the proposal of Sommers and Englebretsen, and so, we would have to add another rule to the SYLL+ framework: 3d. If two premises are universal, the conclusion may not be particular (cf. Note 9).

8 These examples do not necessarily express the authors' opinions.

${ }^{9}$ For the valid inferential patterns that need existential import, like aat-l or aak- 1 , the only requirement is to add the missing implicit premise that states the existence of the minor term, namely, something akin to $+\mathrm{S}^{0}+\mathrm{S}^{0}$ : such addition allows the introduction of the valid patterns that appear in Table 8 but are absent in Table 12 .
} 


\begin{tabular}{|c|c|c|c|}
\hline \multicolumn{4}{|c|}{ (Continuation Table 12) } \\
\hline & Figure 2 & Figure 3 & Figure 4 \\
\hline \multirow{8}{*}{ With "few" } & $a b b$ & & \multirow{8}{*}{$\begin{array}{l}\text { pai } \\
\text { epo }\end{array}$} \\
\hline & abd & & \\
\hline & $\mathrm{abg}$ & pai & \\
\hline & abo & epo & \\
\hline & epb & bao & \\
\hline & epd & api & \\
\hline & epg & & \\
\hline & epo & & \\
\hline
\end{tabular}

Table 13 - An invalid inference: kaa-1

\begin{tabular}{lll}
\hline & Proposition & Representation \\
\hline 1. & Many homeless are ill. & $+\mathrm{H}^{3}+\mathrm{I}^{0}$ \\
2. & This guy is homeless. & $-\mathrm{g}^{0}+\mathrm{H}^{0}$ \\
$\sharp$ & This guy is ill. & $-\mathrm{g}^{0}+\mathrm{I}^{0}$ \\
\hline
\end{tabular}

Table 14 - An invalid inference: kak-3

\begin{tabular}{lll}
\hline & Proposition & Representation \\
\hline 1. & Many Germans are white. & $+\mathrm{G}^{1}+\mathrm{W}^{0}$ \\
2. & Germans are European. & $-\mathrm{G}^{0}+\mathrm{E}^{0}$ \\
H & Many Europeans are white. & $+\mathrm{E}^{1}+\mathrm{W}^{0}$ \\
\hline
\end{tabular}

Table 15 - A valid inference: bao-3

\begin{tabular}{lll}
\hline & Proposition & Representation \\
\hline 1. & Few cars are hybrid. & $+\mathrm{C}^{3}-\mathrm{H}^{0}$ \\
2. & All cars are expensive. & $-\mathrm{C}^{0}+\mathrm{E}^{0}$ \\
$\vdash \quad$ Some expensive cars are not hybrid. & $+\mathrm{E}^{0}-\mathrm{H}^{0}$ \\
\hline
\end{tabular}

Table 16 - A valid inference: etg-2

\begin{tabular}{lll}
\hline & Proposition & Representation \\
\hline 1. & No fool is a citizen. & $-\mathrm{F}^{0}-\mathrm{C}^{0}$ \\
2. & Most voters are citizens. & $+\mathrm{V}^{2}+\mathrm{C}^{0}$ \\
$\vdash \quad$ Many voters are not fools. & $+\mathrm{V}^{1}-\mathrm{F}^{0}$ \\
\hline
\end{tabular}

As we can see from these examples, the $\mathrm{TFL}^{+}$framework gains the advantages of an algebraic method (a reduction of a complex set of rules to a simple and unified formal approach) and, at the same time, it gains the advantages of a theory of syllogisms with non-classical quantifiers (an assessment of a wide range of common sense inference patterns that extends the scope of traditional syllogistic).

\section{Step 3. Reliability}

Finally, we provide some evidence that this tweaked syllogistic is reliable in so far as the modified $\mathrm{TFL}^{+}$procedure is equivalent to the rules of the $\mathrm{SYLL}^{+}$ framework (provided we add the rule 3d, that if two premises are universal, the conclusion may not be particular). In short, for syllogisms at level 0 of quantification, $\mathrm{TFL}^{+}$and SYLL $\mathrm{L}^{+}$collapse. For the rest of syllogisms, rules $1 \mathrm{a}, 1 \mathrm{~b}, 2 \mathrm{a}, 2 \mathrm{~b}$, and $2 \mathrm{c}$ of the SYLL ${ }^{+}$framework are preserved by conditions i) and ii) of the modified plus- 
minus algebra method of decision; while rules 3a, 3b, and 3c (and 3d) are preserved by condition iii) (and ii)). So, let us say a syllogism is $\mathrm{SYLL}_{+}^{+}$(i.e., it is valid in the SYLL $^{+}$framework) if and only if it is $\mathrm{TFL}_{+}^{+}$(i.e., it is valid in the modified plusminus algebra of $\mathrm{TFL}^{+}$):

Proposition 1 (Reliability) A syllogism is $\mathrm{SYLL}^{+}{ }_{\vdash}$ if and only if it is $\mathrm{TFL}^{+}{ }_{\vdash}$.

Consider that, at level 0 of quantification, the proof is trivial: all $\mathrm{SYLL}^{+}$ syllogisms are $\mathrm{TFL}^{+}$, and vice versa. But for the remaining syllogisms, regard: if a syllogism is $\mathrm{SYLL}^{+}{ }_{{ }^{\prime}}$, then it is $\mathrm{TFL}^{+}$. For reductio, suppose $S$ is an arbitrary syllogism that is $\mathrm{SYLL}^{+}$but is not $\mathrm{TFL}^{+}{ }$. Then, $S$ follows the rules of the $\mathrm{SYLL}^{+}$ framework but violates at least one condition of the modified plus-minus algebra of $\mathrm{TFL}^{+}$. Let us list the conditions that make $S$ a SYLL ${ }_{-}$, syllogism: (a) If $S$ follows rule la, at least one middle term of $S$ has the minus sign. (b) If $S$ follows rule lb, at least one term in the conclusion has the minus sign or no term in the conclusion has the minus sign. (c) If $S$ follows 2 a, at least one premise has a predicate-term with a plus sign. (d) If $S$ follows rules $2 \mathrm{~b}$ or $2 \mathrm{c}$, the conclusion and one premise of $S$ must have a predicate-term with a minus sign. (e) If $S$ follows $3 a$, the level of quantification of one premise is 3 and the level of quantification of the conclusion is less or equal than 3. (f) If $S$ follows 3b, the level of quantification of one premise is 2 and the level of the conclusion is less or equal than 2 . (g) If $S$ follows 3c, the level of quantification of one premise is 1 and the level of the conclusion is less or equal than 1. Finally, (h) if $S$ follows 3d, the conclusion of $S$ must have a subjectterm with a minus sign.

By taking the adequate combinations of the above conditions that rule out the application of condition (h) (because the application of $(\mathrm{h})$ is already taken into consideration at the level 0 of quantification), we can construct a set of arbitrary valid syllogisms for any terms X, Y, Z. For example, combination I results from applying the sequence of conditions (a), (b), (c), (e), (f), and (g). The remaining combinations are displayed in Table 17.

Table 17 - Valid syllogistic patterns in TFL+ according to the SYLL+ rules

\begin{tabular}{|c|c|c|c|}
\hline I & II & III & IV \\
\hline 1. $-Y^{0}+Z^{0}$ & 1. $-Y^{0}-Z^{0}$ & 1. $-\mathrm{Z}^{0}+\mathrm{Y}^{0}$ & 1. $-Z^{0}-Y^{0}$ \\
\hline 2. $+\mathrm{X}^{3,2,1,0}+\mathrm{Y}^{0}$ & 2. $+\mathrm{X}^{3,2,1,0}+\mathrm{Y}^{0}$ & 2. $+\mathrm{X}^{3,2,1,0}-\mathrm{Y}^{0}$ & 2. $+\mathrm{X}^{3,2,1,0}+\mathrm{Y}^{0}$ \\
\hline$\vdash \quad+X^{3,2,1,0}+Z^{0}$ & $\vdash \quad+\mathrm{X}^{3,2,1,0}-\mathrm{Z}^{0}$ & $+\mathrm{X}^{3,2,1,0}-\mathrm{Z}^{0}$ & $\vdash \quad+X^{3,2,1,0}-Z^{0}$ \\
\hline V & VI & VII & VIII \\
\hline 1. $-Y^{0}+Z^{0}$ & 1. $-Y^{0}+Z^{0}$ & 1. $+\mathrm{Z}^{3,2,1,0}+\mathrm{Y}^{0}$ & 1. $\quad-Z^{0}-Y^{0}$ \\
\hline 2. $+\mathrm{Y}^{3,2,1,0}+\mathrm{X}^{0}$ & 2. $+\mathrm{Y}^{3,2,1,0}-\mathrm{X}^{0}$ & 2. $-Y^{0}+X^{0}$ & 2. $+\mathrm{Y}^{3,2,1,0}+\mathrm{X}^{0}$ \\
\hline$\vdash \quad+\mathrm{X}^{0}+\mathrm{Z}^{0}$ & $\vdash \quad+\mathrm{Z}^{0}-\mathrm{X}^{0}$ & $\vdash \quad+Z^{3,2,1,0}+X^{0}$ & $\vdash \quad+X^{0}-Z^{0}$ \\
\hline
\end{tabular}

Clearly, combination I is $\mathrm{TFL}_{r}^{+}:$i) the sum of the premises takes away the term-schema $\mathrm{Y}$ and yields the conclusion with terms $+\mathrm{X}+\mathrm{Z}$; ii) the number of conclusions with particular quantity is the same as the number of premises with particular quantity (in this case such number is 1); and iii) the level of quantification of the conclusion is lesser or equal than the maximum level of quantification of the premises: when premise 2 is $+\mathrm{X}^{3}+\mathrm{Y}^{0}$, the conclusion might be $+\mathrm{X}^{3}+\mathrm{Z}^{0}$, or $+\mathrm{X}^{2}+\mathrm{Z}^{0}$, or $+\mathrm{X}^{1}+\mathrm{Z}^{0}$, or $+\mathrm{X}^{0}+\mathrm{Z}^{0}$; when premise 2 is $+\mathrm{X}^{2}+\mathrm{Y}^{0}$, the conclusion might be 
$+\mathrm{X}^{2}+\mathrm{Z}^{0}$, or $+\mathrm{X}^{1}+\mathrm{Z}^{0}$, or $+\mathrm{X}^{0}+\mathrm{Z}^{0}$; when premise 2 is $+\mathrm{X}^{1}+\mathrm{Y}^{0}$, the conclusion might be $+\mathrm{X}^{1}+\mathrm{Z}^{0}$, or $+\mathrm{X}^{0}+\mathrm{Z}^{0}$; finally, when premise 2 is $+\mathrm{X}^{0}+\mathrm{Y}^{0}$, the $\mathrm{TFL}^{+}$framework collapses with the SYLL ${ }^{+}$framework and so the conclusion is $+\mathrm{X}^{0}+\mathrm{Z}^{0}$. The remaining combinations also comply with conditions i), ii), and iii).

So, the arbitrary syllogisms defined in Table 17 are $\mathrm{TFL}^{+}$, as they comply with conditions i), ii), and iii) of the modified plus-minus algebra, but $S$ must have the form of one of such syllogisms, since $S$ was constructed by an application of a sequence of conditions that make $S$ a SYLL $^{+}$, syllogism. Hence, $S$ must also be $\mathrm{TFL}^{+}{ }_{\vdash}$, but this contradicts the assumption that $S$ is $\mathrm{SYLL}^{+}$but is not $\mathrm{TFL}^{+}{ }_{\vdash}$.

Conversely, from right to left, the outline is more or less direct: if we write down the syllogisms that are $\mathrm{TFL}^{+}{ }_{r}$, we will see that they correspond to some syllogism already listed in Table 8 (provided we take into account what we have explained in Notes 8 and 9).

This sketch of proof indicates that the $\mathrm{TFL}^{+}$framework is reliable in that all valid syllogisms in the SYLL ${ }^{+}$framework can be obtained by applying the modified plus-minus algebra method of decision of $\mathrm{TFL}^{+}$, and vice versa, all syllogisms that can be obtained by applying the modified plus-minus algebra method of decision are valid syllogisms in the $\mathrm{SYLL}^{+}$framework. But moreover, since $\mathrm{TFL}^{+}$is also an extension of TFL, it is able to perform intermediate relational syllogistic, as in the next example (Table 18):

Table 18 - A valid intermediate relational syllogism in TFL+

\begin{tabular}{lll}
\hline & Proposition & Representation \\
\hline 1. & Many philosophers are logicians. & $+\mathrm{P}^{1}+\mathrm{L}^{0}$ \\
2. All logicians give flowers to many girls. & $-\mathrm{L}_{1}^{0}+\left(+\mathrm{F}_{12}+\mathrm{G}_{2}{ }^{1}\right)$ \\
$\vdash \quad$ Many philosophers give flowers to many girls. & $-\mathrm{P}_{1}^{1,0}+\left(+\mathrm{F}_{12}+\mathrm{G}_{2}{ }^{1,0}\right)$ \\
\hline
\end{tabular}

\section{Concluding remarks}

In this short contribution we have attempted to join a plus-minus algebra for syllogistic (as developed by Sommers and Englebretsen) together with an extension of syllogistic with non-classical quantifiers (as proposed by Peterson and Thompson). The result is a reliable intermediate syllogistic that copes with a wide range of common sense logical patterns but with the virtues of an algebraic approach.

This intermediate syllogistic, based upon ideas taken from the notion of generalized quantifier (MOSTOWSKI, 1957), intermediate syllogistic (PETERSON, 1979; THOMPSON, 1982), and term logic (SOMMERS, 1967, 1982; SOMMERS and ENGLEBRETSEN，2000; ENGLEBRETSEN，1987，1996; ENGLEBRETSEN and SAYWARD, 2011) is different, for example, from the approaches proposed by (WESTERSTÅHL, 1989) or (MURPHREE, 1998) because, respectively, this version uses term logic à la Sommers, and not first order logic; and vague intermediate quantifiers, and not precise numerical-wise quantifiers. Thus, we believe this version is not only novel, but also quite promising, not just as yet another critical thinking tool or didactic contraption, but as a research device for probabilistic reasoning (in so far as it could be used to represent probabilistic reasoning (THOMPSON (1986), diagrammatic reasoning (as it would find its natural home in a tweaked version of linear diagrams (ENGLEBRETSEN, 1991); Pagnan (2012), psychology (as it could be 
used to approximate a richer psychological account of syllogistic (KHEMLANI and JOHNSON-LAIRD, 2012), artificial intelligence (as it could be used to develop a tweaked inferential engine for Aristotelian databases (MOZES, 1989), and of course, philosophy of logic (as it promotes the revision and revival of term logic (cf. (VEATCH, 1970; SOMMERS, 1982; ENGLEBRETSEN, 1996; ENGLEBRETSEN and SAYWARD, 2011)) as a tool that might be more interesting and powerful than once it seemed (CARNAP, 1930); Geach (1962, 1980).

\section{References}

CARNAP, Rudolf. Die alte und die neue Logik. Erkenntnis, 1, 12-26, 1930.

ENGLEBRETSEN, George. The New Syllogistic. Peter Lang, 1987.

ENGLEBRETSEN, George. Linear Diagrams for Syllogisms (with Relationals). Notre Dame J Formal Logic, v. 33, n. 1, p. 37-69, 1991.

ENGLEBRETSEN, George. Something to Reckon with: The Logic of Terms. University of Ottawa Press, 1996.

ENGLEBRETSEN, George and SAYWARD, Charles. Philosophical Logic: An Introduction to Advanced Topics. Bloomsbury Academic, 2011.

GEACH, Peter. Reference and Generality: An Examination of Some Medieval and Modern Theories. Cornell University Press, 1962.

GEACH, Peter. Logic Matters. University of California Press, 1980.

KHEMLANI, Sangeet and JOHNSON-LAIRD, Philip. Theories of the Syllogism: a Meta-Analysis. Psychological Bulletin, 427-457, 2012.

KUHN, Steven. An Axiomatization of Predicate Functor Logic. Notre Dame J Formal Logic, v. 24, n. 2, p. 233-241, 1983.

MOSS, Lawrence. Natural Logic. In: LAPPIN, S., FOX, C. (eds.) The Handbook of Contemporary Semantic Theory, John Wiley \& Sons, 2015.

MOSTOWSKI, Anderzj. On a Generalization of Quantifiers. Fundamenta Mathematicae, v. 44, n. 2, p.12-36, 1957.

MOZES, Eyal. A Deductive Database Based on Aristotelian Logic. Journal of Symbolic Computation 7(5), p. 487-507, 989.

MURPHREE, Wallace. Numerical term logic. Notre Dame J Formal Logic, 39(3), p. 346-362, 1998.

NOAH, Aris. Predicate-functors and the Limits of Decidability in Logic. Notre Dame J Formal Logic, v. 21, n. 4, p. 701-707, 1980.

NOAH, Aris. Sommers's Cancellation Technique and the Method of Resolution. In: Oderberg, D. (ed.) The Old New Logic: Essays on the Philosophy of Fred Sommers, Bradford, p. 169-182, 2005.

PAGNAN, Ruggero. A Diagrammatic Calculus of Syllogisms. Journal of Logic, Language and Information, v. 21, n. 3, p. 347-364, 2012.

PETERSON, Philip. On the Logic of "Few", "Many", and "Most". Notre Dame J Formal Logic, v. 20, n. 1, p.155-179, 1979. 
QUINE, Willard Van Orman. Predicate Functor Logic. In: FENSTAD, J.E. (ed.) Proceedings of the Second Scandinavian Logic Symposium, North-Holland, 1971.

SOMMERS, Fred. On a Fregean Dogma. In: LAKATOS, I. (ed.) Problems in the Philosophy of Mathematics, Studies in Logic and the Foundations of Mathematics, v. 47, Elsevier, pp. 47-81, 1967.

SOMMERS, Fred. The Logic of Natural Language. Oxford University Press, 1982.

SOMMERS, Fred. Intelectual Autobiography. In: ODERBERG, D. (ed.) The Old New Logic: Essays on the Philosophy of Fred Sommers, Bradford, p. 1-24, 2005.

SOMMERS, Fred and ENGLEBRETSEN, George. An Invitation to Formal Reasoning: The Logic of Terms. Ashgate, 2000.

THOMPSON, Bruce. Syllogisms using "Few", "Many", and "Most". Notre Dame J Formal Logic, v. 23, n. 1, p. 75-84, 1982.

THOMPSON, Bruce. Syllogisms with Statistical Quantifiers. Notre Dame J Formal Logic 27(1):93-103, 1986.

VEATCH, Henry Babcock. Intentional Logic: a Logic Based on Philosophical Realism. Archon Books, 1970.

WESTERSTÅL, Dag. Aristotelian Syllogisms and Generalized Quantifiers. Studia Logica, v. 48, n. 4, p. 577-585, 1989. 


\section{Appendix A. Rules of inference for TFL}

In this Appendix we expound the rules of inference for TFL as they appear in (Englebretsen, 1996).

\section{Rules of immediate inference}

1. Premise $(P)$ : Any premise or tautology can be entered as a line in proof. (Tautologies that repeat the corresponding conditional of the inference are excluded. The corresponding conditional of an inference is simply a conditional sentence whose antecedent is the conjunction of the premises and whose consequent is the conclusion.)

2. Double Negation $(D N)$ : Pairs of unary minuses can be added or deleted from a formula (i.e., --X=X).

3. External Negation $(E N)$ : An external unary minus can be distributed into or out of any phrase (i.e., $-( \pm \mathrm{X} \pm \mathrm{Y})=\overline{\mathrm{T}} \mp \mathrm{Y})$.

4. Internal Negation (IN): A negative qualifier can be distributed into or out of any predicate-term (i.e., $\pm \mathrm{X}-( \pm \mathrm{Y})= \pm \mathrm{X}+( \pm \mathrm{Y})$ ).

5. Commutation (Com): The binary plus is symmetric (i.e., $+X+Y=+Y+X)$.

6. Association (Assoc): Thebinaryplusisassociative (i.e., $+\mathrm{X}+(+\mathrm{Y}+\mathrm{Z})=+(+\mathrm{X}+\mathrm{Y})+\mathrm{Z})$.

7. Contraposition (Contrap): The subject- and predicate-terms of a universal affirmation can be negated and can exchange places (i.e., $-\mathrm{X}+\mathrm{Y}=-(-\mathrm{Y})+(-\mathrm{X})$ ).

8. Predicate Distribution (PD): A universal subject can be distributed into or out of a conjunctive predicate (i.e., $-\mathrm{X}+(+\mathrm{Y}+\mathrm{Z})=+(-\mathrm{X}+\mathrm{Y})+(-\mathrm{X}+\mathrm{Z})$ ) and a particular subject can be distributed into or out of a disjunctive predicate (i.e., $+\mathrm{X}+(-$ $(-\mathrm{Y})-(-\mathrm{Z}))=--(+\mathrm{X}+\mathrm{Y})--(+\mathrm{X}+\mathrm{Z}))$.

9. Iteration $(I t)$ : The conjunction of any term with itself is equivalent to that term (i.e., $+\mathrm{X}+\mathrm{X}=\mathrm{X}$ ).

\section{Rules of mediate inference}

1. $(D O N)$ : If a term, $\mathrm{M}$, occurs universally quantified in a formula and either $\mathrm{M}$ occurs not universally quantified or its logical contrary occurs universally quantified in another formula, deduce a new formula that is exactly like the second except that $M$ has been replaced at least once by the first formula minus its universally quantified $\mathrm{M}$.

2. Simplification (Simp): Either conjunct can be deduced from a conjunctive formula; from a particularly quantified formula with a conjunctive subject-term, deduce either the statement form of the subject-term or a new statement just like the original but without one of the conjuncts of the subject-term (i.e., from $+(+\mathrm{X}+\mathrm{Y}) \pm \mathrm{Z}$ deduce any of the following: $+\mathrm{X}+\mathrm{Y},+\mathrm{X} \pm \mathrm{Z}$, or $+\mathrm{Y} \pm \mathrm{Z})$, and from a universally quantified formula with a conjunctive predicate- term deduce a new statement just like the original but without one of the conjuncts of the predicateterm (i.e., from $-\mathrm{X} \pm(+\mathrm{Y}+\mathrm{Z})$ deduce either $-\mathrm{X} \pm \mathrm{Y}$ or $-\mathrm{X} \pm \mathrm{Z})$.

3. Addition $(A d d)$ : Any two previous formulae in a sequence can be conjoined to yield a new formula, and from any pair of previous formulae that are both universal affirmations and share a common subject-term a new formula can be 
derived that is a universal affirmation, has the subject-term of the previous formulae, and has the conjunction of the predicate- terms of the previous formulae as its predicate-term (i.e., from $-\mathrm{X}+\mathrm{Y}$ and $-\mathrm{X}+\mathrm{Z}$ deduce $-\mathrm{X}+(+\mathrm{Y}+\mathrm{Z})$ ).

\section{Sobre o autor}

\section{José Martin Castro Manzano}

Licenciado en Filosofía y Maestro en Inteligencia Artificial por la Universidad Veracruzana (UV), Doctor en Filosofía de la Ciencia por la Universidad Nacional Autónoma de México (UNAM), y tiene formación en Ciencias Computacionales por la Benemérita Universidad Autónoma de Puebla (BUAP).

Miembro del Sistema Nacional de Investigadores (Nivel 1); es Miembro de la Academia Mexicana de Lógica, del Grupo Mexicano de Lógica y Computación, de la Sociedad de Lógica, Metodología y Filosofía de la Ciencia en España, y ha sido socio de la Sociedad Mexicana de Inteligencia Artificial

Recebido em 03/01/2019

Aprovado em 12/07/2019

\section{Como referenciar esse artigo}

MANZANO, José Martin Castro. An intermediate term functor logic. Argumentos: Revista de Filosofia. Fortaleza, ano 11, n. 22, p. 17-31, jul.-dez. 2019. 